\title{
Comparison of on-treatment Noninvasive Markers of Liver Fibrosis Among Patients with HBV and $\mathrm{HBV} / \mathrm{HIV}$ Coinfection in Ethiopia
}

Amir Sultan ( $\sim$ amirs08444@gmail.com )

Addis Ababa University

Wondwossen Amogne

Addis Ababa University

\section{Research Article}

Keywords: Ethiopia, Hepatitis B, HIV, APRI, FIB4

Posted Date: January 17th, 2022

DOI: https://doi.org/10.21203/rs.3.rs-1232481/v1

License: (c) (i) This work is licensed under a Creative Commons Attribution 4.0 International License.

Read Full License 


\section{Abstract}

Background: Noninvasive markers of liver fibrosis have gained central importance in the assessment of patients with liver diseases. Among patients with Hepatitis B and HIV coinfection, the role of these noninvasive serum markers has not been well studied in the Ethiopian setup.

Methodology: A hospital-based cross-sectional study was conducted at Tikur Anbessa Hospital ART clinic. Patients with HIV and HBV coinfection were recruited from the clinic, and a second comparison group with HBV mono-infection was recruited from the liver clinic. All patients were on tenofovir-based treatment of hepatitis B. Baseline demographic and laboratory values comparison between the two groups were conducted. For APRI, a cutoff of 0.5 and 1.5 was used to assess fibrosis; and for FIB4, cutoffs of 1.45 and 3.25 were used as the lower and higher cutoff, respectively.

Result: A total of 74 patients were included, of which 24 patients were with HBV/HIV coinfection and 50 were with HBV mono-infection. The median age of participants was 37, and the majority were from Addis Ababa. Prevalence of diabetes and alcohol use was comparable in both groups. The median platelet count among patients with coinfection was 220,000 ( IQR 159000 - 277000), while among the monoinfected patients, it was 166000 ( 87750-227500). The APRI score among the coinfected patients was $0.4(0.23-0.59)$ while it was $0.57(0.4-1.4)(p=0.01)$. The FIB4 was $1.1(0.69-2.03)$ among coinfected patients, while it was $1.7(1-2.9)$ among monoinfected patients $(p=0.01)$. Using a lower and higher APRI and FIB4 cutoffs, both groups had a statistically nonsignificant difference. However, the platelet count using a cutoff of 1500000 was significantly lower among patients with HBV monoinfection.

Conclusion; Our data indicate that patients with HIV/HBV coinfection on treatment had comparable noninvasive liver fibrosis marker profiles compared to patients with HBV mono-infection on therapy. On the majority of the parameters, there was a trend towards a better profile among patients with coinfection, which might be explained by early initiation of tenofovir therapy as part of HIV treatment.

\section{Introduction}

Liver diseases and HIV are among the commonest causes of morbidity and mortality in Ethiopia(1). As the mode of transmission of viral hepatitis and HIV are similar(2),(3), there is an increased prevalence of coinfection in some segments of the general population. This also leads to an increased occurrence of coinfection with Hepatitis B and C. However, due to the robust transmission capacity of the hepatotropic viruses, especially hepatitis $B$ the prevalence of the condition is much higher than the HIV prevalence(3). In Ethiopia, since 2005, there is a national ART(4) treatment program which follows guidelines issued by the Ministry of Health and the WHO. It is well known that drugs used to treat HIV like Tenofovir and Lamuvidine are also used to treat Hepatitis B(5). In the country, there is a large population of HIV and HBV coinfected individuals receiving treatment for hepatitis B via the ART program(4). 
One of the significant issues in the treatment of Hepatitis B is the assessment of the degree of liver injury and fibrosis(6). This is very much important because those patients with advanced liver fibrosis are at increased risk of progression, liver failure, liver cancer and death(7),(8),(9). Because of this, those patients with advanced fibrosis are given priority in the treatment of hepatitis $B$.

Classically, assessment of liver fibrosis is done by liver biopsy(10), (11). However, liver biopsy is an invasive procedure and associated with much higher morbidity(12). The risk of major bleeding associated with the procedure is estimated to be around $1 \%(13)$. In addition, there is an inherent risk of sampling error(14). In the last two decades, there has been a significant decline in the number of liver biopsies performed because of these(15). The other main reason is the development of new noninvasive tools of liver fibrosis assessment(16). These tests enable practitioners to get information about the state of liver fibrosis of individual patients without needing a needle biopsy. With the additional emergence of novel treatment options for viral hepatitis, an increased number of patients need evaluation for liver disease. Tests developed in this regard are broadly divided into two. One is radiologic-based tests like the Transient Elastography (Fibroscan)(17) and Acoustic Radiation force Elastography (ARFI)(18),(19). The second is blood-based tests like the AST to Platelet Ratio Index (APRI)(20), (21), Fib-4, Fibrotest(22) and GPR(23),(24). The blood-based tests have attracted attention, especially in resource-limited setups(25), (26). As the significant patient risk and high cost of liver biopsy prohibit its applicability, serum-based tests are being used more often in developing countries(27).

One group of patients where these tests are not extensively studied and validated is in patients with HIV coinfection, especially in sub-Saharan Africa. The main reason is that patients with HIV infection have increased liver fibrosis independent of the coinfection, and some of the parameters used in the tests, like platelet count, could be affected by HIV infection(28). However, the modification of these factors with antiviral treatment is not well studied.

According to studies done over the last three decades, the prevalence of chronic HBV infection is estimated from 7-9 \% in Ethiopia (29). Up until 2016, there was no affordable treatment for Hepatitis B in the country. However, the patients with HIV coinfection were getting the drugs like Lamivudine and Tenofovir via the ART program. This national ART program has been running for the past 15 years and was the only way patients could get antivirals(4). In 2016 Tenofovir became available in the market to treat Hepatitis B mono-infection.

The role of the noninvasive tools of liver fibrosis is paramount in Ethiopia currently as these are the tests utilized to decide for treatment of Hepatitis B monoinfected patients. In addition, it also indicates the degree of liver damage and suggests possible interventions to be undertaken.

\section{Methods}

The study was conducted at Tikur Anbessa Specialized Hospital, the largest referral hospital in the country. Recruitment was made among patients attending regular care at the HIV care clinic and the liver clinic of the hospital. HIV/HBV coinfected patients were mainly recruited from the ART clinic and provided 
with informed consent. Inclusion criteria were patients who were on TDF based ART regimen. Those patients not on the stated regimen were excluded from inclusion. In addition, those patients with additional Hepatitis $\mathrm{C}$ infection were excluded.

For the HBV mono-infected individuals, inclusion was restricted for TDF-based therapy. Patients not yet started on treatment, those with concomitant Hepatitis $C$ infection, those with hepatocellular carcinoma were excluded from inclusion. A 1:2 ratio was used as such for each coinfected patient 2 HBV monoinfected patients were recruited to compare findings.

\section{Laboratory Parameters}

Liver enzymes, i.e., Alanine aminotransferase (ALT) and Aspartate aminotransferase (AST), were determined for the biochemical parameters. Platelet count was determined for all patients, and results were recorded as $\times 10^{6}$. In addition, Hemoglobin, bilirubin level, creatinine, and serum INR were documented. For patients with HIV/HBV coinfection, CD4 count was determined and result included.

Noninvasive indicators of liver fibrosis were calculated according to established literature in the field.

\section{APRI = (AST / ULN AST) / (Platelet count $x$ 100)}

\section{FIB-4 $=($ Age in years $x$ AST $) /($ Platelet count $* \sqrt{A L T})$}

Cutoffs were determined according to the recent WHO guideline; for APRI, the lower cutoff 0.5 was used to detect significant fibrosis; similarly, for FIB-4 1.45 was used. For advanced fibrosis, the higher cutoffs 1.5 and 3.25 were used for APRI and Fib-4, respectively.

\section{Data entry and statistical analysis}

Data were collected by a trained data collector at the two clinics. Data was entered into Microsoft Excel ( Seattle, Washington). The collected data was then subsequently entered into the Statistical Product Service Solutions (SPSS) version 23.0 (Chicago, IL) for analysis. Categorical data were presented as median and interquartile range; Chi-square and Mann Whitney test was used to compare categorical variables and identify the statistically significant association. A P-value of less than 0.05 was used to define statistically significant differences.

\section{Ethics}

Ethical clearance was granted from the Addis Ababa University College of Health Sciences (AAU-CHS) institutional review board (IRB). All patients were provided with a written informed consent form in the 
local language.

\section{Results}

\section{Patients and demographics}

One hundred fifty patients with HBV mono-infection were assessed at the liver clinic. Of these 50 patients who were on TDF based antiviral were recruited for the study. Of 1200 patients who were on followup at the ART clinic; 24 patients fulfilled the criteria for inclusion and were recruited for the study ( Table 1 ). Among the coinfected patients, $58 \%$ 
Table 1

Baseline Characteristics of patients with HBV/HIV coinfection and HBV monoinfection

\begin{tabular}{|c|c|c|c|}
\hline Characteristic & $\begin{array}{l}\text { HBV/HIV coinfection }(n= \\
24)\end{array}$ & $\begin{array}{l}\text { HBV monoinfection ( } \\
\mathrm{n}=50)\end{array}$ & $\begin{array}{l}P \\
\text { value }\end{array}$ \\
\hline Age ( Median, IQR) & $37(35-43)$ & $35(29-47)$ & 0.52 \\
\hline Sex (Male, \%) & $14(58 \%)$ & $34(68 \%)$ & 0.06 \\
\hline \multicolumn{4}{|l|}{ Address } \\
\hline Addis Ababa & $12(50 \%)$ & $26(52 \%)$ & 0.25 \\
\hline Oromia & $5(21 \%)$ & $12(24 \%)$ & 0.15 \\
\hline Amhara & $5(21 \%)$ & $4(8 \%)$ & 0.04 \\
\hline Others & $2(8 \%)$ & $8(16 \%)$ & 0.06 \\
\hline Diabetes (Yes) & $2(8 \%)$ & $3(6 \%)$ & 0.12 \\
\hline Alcohol History (Significant) & $3(12.5 \%)$ & $6(12 \%)$ & 0.53 \\
\hline \multicolumn{4}{|l|}{ Laboratory Parameters } \\
\hline ALT IU/I (Median, IQR) & $29(18-34)$ & $34(21-40)$ & 0.16 \\
\hline AST IU/I (Median, IQR) & $31(22-43)$ & $37(27-56)$ & 0.14 \\
\hline Hemoglobin g/dl (Median, IQR) & $13(11.9-14.8)$ & $12.5($ IQR $11.4-14)$ & 0.2 \\
\hline Platelet Count $10^{6}$ (Median, IQR) & $\begin{array}{l}220500(159000- \\
277000)\end{array}$ & $166000(87750-227500)$ & 0.007 \\
\hline INR (Median, IQR) & $1(0.8-1.3)$ & $1.3(1.0-1.6)$ & 0.08 \\
\hline Bilirubin, mg/dl (Median, IQR) & $0.95(0.77-2.2)$ & $1(0.8-1.8)$ & 0.2 \\
\hline Creatinine mg/dl (Median, IQR) & $1(0.6-1.1)$ & $1(0.8-1.2)$ & 0.15 \\
\hline CD4 count (Median, IQR) & $191(134-370)$ & & \\
\hline $\begin{array}{l}\text { ART duration, months (Median, } \\
\text { IQR) }\end{array}$ & $72(13-165)$ & & \\
\hline APRI (Median, IQR) & $0.4(0.23-0.59)$ & $0.57(0.4-1.4)$ & 0.014 \\
\hline FIB4 (Median, IQR) & $1.1(0.69-2.03)$ & $1.7(1-2.9)$ & 0.013 \\
\hline
\end{tabular}

were male and the median age of participants was 37 (IQR 35-41) and majority of the patients came from Addis Ababa ( $50 \%$ ) followed by Oromia and Amhara regions ( $21 \%$ each).

In the HBV monoinfected group, the median age of participants was 35 (IQR 28-41) and $80 \%$ were males. The majority came from Addis Ababa ( $52 \%$ ) followed by Oromia ( $24 \%$ ) and Amhara ( $8 \%$ ) regions. The 
number of patients with diabetes and patients with significant alcohol use was comparable in both groups.

\section{Laboratory and noninvasive test parameters}

Among patients with HBV/HIV coinfection, the median AST was 31 (IQR 22 -43) and median ALT was 29 ( IQR 18 - 34). Median platelet count was 220,500 (IQR 159,000-270,000). The patients had a median creatinine value of 1 (IQR 0.6-1.1) and an INR of 1.0 (IQR 0.8 - 1.3). The Median CD4 count was 191 ( IQR $134-370$ ), and patients were on ART for a median of 72 months ( IQR $13-165$ ).

The median APRI score was 0.4 ( IQR 0.23 - 0.59) and that of FIB4 was 1.1 (IQR $0.69-2.03$ )

Patients with HBV mono-infection had a median AST of 37 (IQR 27 - 56) and ALT of 34 (IQR 21- 40). Creatinine was $1(0.8-1.2)$ and the INR was 1.3 (IQR 1.0 -1.6). Median Platelet count was 166,000 (IQR 87750-227500). The median APRI determined was 0.57 ( $0.4-1.4)$ and FIB4 was 1.78 (IQR 1- 2.9).

Table 2

Comparison of APRI, FIB4 and Platelet counts scores among patients with $\mathrm{HBV} / \mathrm{HIV}$ coinfection and HBV monoinfection

\begin{tabular}{|c|c|c|c|}
\hline & HBV/HIV coinfection & HBV monoinfection & $P$ Value \\
\hline APRI low cutoff & & & 0.08 \\
\hline$<0.5$ & $16(67 \%)$ & $22(44 \%)$ & \\
\hline$\geq 0.5$ & $8(33 \%)$ & $28(56 \%)$ & \\
\hline APRI high cutoff & & & 0.12 \\
\hline$<1.5$ & $22(91.7 \%)$ & $38(76 \%)$ & \\
\hline$\geq 1.5$ & $2(8.3 \%)$ & $12(24 \%)$ & \\
\hline FIB4 low cutoff & & & 0.08 \\
\hline$<1.45$ & $15(62.5 \%)$ & $20(40 \%)$ & \\
\hline$\geq 1.45$ & $9(37.5 \%)$ & $30(60 \%)$ & \\
\hline FIB4 high cutoff & & & 0.09 \\
\hline$<3.25$ & $23(95.8 \%)$ & $40(80 \%)$ & \\
\hline$\geq 3.25$ & $1(4.2 \%)$ & $10(20 \%)$ & \\
\hline Platelet count & & & 0.04 \\
\hline$<150,000$ & $5(21 \%)$ & $23(46 \%)$ & \\
\hline$\geq 150,000$ & 19 (79\%) & $27(54 \%)$ & \\
\hline
\end{tabular}




\section{Cutoff values for Noninvasive markers}

Two Cutoffs were used for both noninvasive markers. For APRI score using the lower cutoff of 0.5 to assess for significant fibrosis ; $67 \%$ of coinfected patients had a value less than 0.5 ( Table 2 ). Using the higher cutoff of $1.5 ; 92 \%$ of the coinfected patients fall below the cutoff point. When the same assessment was applied to the HBV monoinfected participants $44 \%$ had a value below 0.5 and $76 \%$ had a value below 1.5. Chi-square test was applied to see for any significant difference between the two groups and the results were not statistically significant $(P=0.08$ and $P=0.12)$ ( Figure 1 \& 2$)$.

For FIB4 similar approach was applied to assess significant fibrosis using two cutoffs of 1.45 and 3.25. Using the lower cutoff, $62.5 \%$ of the coinfected and $40 \%$ of the HBV monoinfected patients had a value below 1.45 . Alternatively using the higher cutoff, $96 \%$ of the coinfected and $80 \%$ of the monoinfected patients had a value below 3.25. On chi-square test for assessment of significant difference between the values among the two groups; the p values were 0.08 and 0.09 for low and high cutoff respectively. ( Figure $3 \& 4$ )

For platelet count comparison, using the count 150,000 to indicate thrombocytopenia; $21 \%$ of the coinfected and $46 \%$ of the monoinfected patients were thrombocytopenic ( $p=0.04)$. (Figure 5 )

\section{Discussion}

Our study tried to indicate the relationship between noninvasive markers of liver fibrosis among patients with HBV mono-infection versus those with HBV-HIV coinfection. Such assessments were not carried out previously in the Ethiopian setup and most studies were carried among treatment naïve groups in Africa.

Our study indicated that patients with HIV/HBV coinfection had a better platelet count compared to those with HBV mono-infection. This is counter to most published literature suggesting that patients with HIV infection are likely to have a low platelet count and hence likely to have elevated noninvasive markers(30). However, the thrombocytopenia in these patients was characterized when the results were compared to the general population and not with a condition known to cause low platelet count, like Hepatitis B. Furthermore, with an adequate duration of HAART therapy, thrombocytopenia has been shown to improve compared to ART naïve individuals(31). The lower platelet count in patients with HBV mono-infection could be attributed to an advanced liver disease even though platelet count is a crude indicator of advanced liver fibrosis. One explanation is that only those with lower platelet count and evidence of liver fibrosis are initiated on antivirals compared to the larger cohort of HBV-infected patients. This indicates that patients with HBV mono-infection might be at a disadvantage when starting antivirals as a significant amount of time is elapsed before the decision to initiate antivirals is made; by the time, patients are already developing more advanced fibrosis. However, the design of our current study is not geared towards such a conclusion, and further studies might be needed with a particular emphasis on the specific point. Among patients with HBV and HIV, previous studies conducted by Iroezindu et al, indicated 
that patients with HIV and HBV coinfection were likely to have a lower platelet count; however, the included patients were those without ART initiation.(32)

Similarly, Patients untreated for HIV and HBV were likely to have a higher APRI score on previous studies. Wandeler and colleagues tried to compare the APRI score of patients with HIV/HBV coinfection in Zambia and Switzerland(33). They showed that those with coinfection had a higher score but this study also used ART untreated patients as the study population. A Study using conducted among participants from the Multicenter AIDS Cohort Study (MACS) also showed a higher APRI score among coinfected individuals. However, the MACS study used both HBV and HCV-infected individuals, and the patients were grouped as Hepatitis Coinfected(34). In addition, the patients with HBV coinfection were not on TDF therapy, and effect of viral hepatitis treatment was not accounted for. A study conducted in Uganda showed that those with HIV/HBV coinfection had a 3 fold increased risk of elevated APRI score, and similarly, the included patients were evaluated before enrollment into the study(35).

A recent South African study by Maponga and colleagues has shown that patients with HIV and HBV coinfection are at an advantage over patients with HBV mono-infection as evidenced by lower HBV viral load, lower APRI score, higher platelet count, and more frequent evaluation by elastography(36). This study included similar patients to our participants and indicated that with adequate antiviral suppression of HBV, patients with HIV coinfection might actually have a better liver parameter than those with monoinfection.

The finding that our patients had a reasonable CD4 count and adequate ART duration might contribute to a better noninvasive assessment profile. Two studies from India indicated that those patients with low CD4 count and HBV coinfection were more likely to have worse liver parameters when compared with those with a higher CD4 count(37),(38). Both showed that patients were more likely to have higher liver enzymes and HBV viral loads if the CD 4 count was low. Similarly, a study in China showed those patients with HBV coinfection were shown to have a lower CD4 count and higher liver enzymes prior to ART initiation(39).

Access to antiviral treatment is also a significant issue that might make patients with HBV monoinfection at a disadvantage compared to those with HIV coinfection. Current HIV treatment guidelines provide treatment access to those with HIV/HBV coinfection, and treatment is provided free of charge in Africa, whereas those with HBV mono-infection have to develop significant fibrosis or elevated liver enzymes to start antiviral treatment. In addition, patients have to pay for their treatment, and in some situations, access might be interrupted.

The strength of our study is that it is the first study from Ethiopia to characterize differences between HBV monoinfected and HIV/HBV coinfected patients in terms of noninvasive markers of liver fibrosis. The study included assessments using dual cutoffs to compensate for loss of sensitivity and specificity by the use of a single value. We also used both APRI and FIB4 markers and these are the most widely used clinical methods to measure liver fibrosis. 
Our study also has different limitations. We did not include transient elastography measurements as the device is not widely available in the country, and it is currently expensive to acquire in most facilities. The inclusion of TE measurement would have helped further strengthen our findings; however, the machine is not available in the continent in most hospitals in Africa and has a limited clinical application. Hepatitis B viral load and e antigen status is not documented for most patients, and the inclusion of this data would have helped to reflect on the association of virologic suppression with liver fibrosis in both groups of patients. However, current guidelines from the WHO forgo a requirement of these tests on decision making to initiate antiviral therapy in resource-limited facilities if there is evidence for significant fibrosis and cirrhosis based on a noninvasive assessment of liver fibrosis.

Our study also relied on already diagnosed patients with HIV/HBV coinfection for inclusion in the study. A significant number of patients might have had the coinfection and not yet been diagnosed on followup. Ideally, all patients on followup at the ART clinic should have been tested for the presence of HBV coinfection; however, due to resource constraints, it was not possible. It is worth noting that the number of coinfected patients on followup is low compared to the estimated prevalence according to published African literature.

\section{Conclusion}

Our study indicated that the noninvasive fibrosis assessment profile of on-treatment patients with $\mathrm{HBV} / \mathrm{HIV}$ coinfection might be better than those with HBV mono-infection. A likely explanation for this is the universal initiation of antiviral therapy in HIV coinfected individuals, contributing to a better overall fibrosis parameter in noninvasive parameters.

\section{Declarations}

\section{Ethical Statements -}

Ethical Clearance received from College of Health Sciences, Addis Ababa University, Institutional Review Board (IRB), Protocol no 001/18/IM. Written informed consent was obtained from participants before the initiation of study. All methods were performed in accordance with the relevant guidelines and regulations.

\section{Consent for publication -}

Not applicable

\section{Availability of Data \& Materials -}


The datasets used and/or analyzed during the current study available from the corresponding author on reasonable request.

\section{Competing Interest -}

None

\section{Funding -}

Study was funded by the Medical Education Partnership Initiative- Junior Faculty (MEPI -JF) Project, Addis Ababa University

\section{Authors Contribution -}

AS wrote the research proposal and oversaw data collection and analysis. WA did an overview of proposal development, methodology and manuscript development. WA supervised the project overall and secured funding.

\section{Acknowledgements -}

Authors want to thank the ART clinic of Tikur Anbessa hospital and MEPI-JF project for the support to conduct the study.

\section{References}

1. Tsega E. Current views on liver diseases in Ethiopia. Ethiop Med J [Internet]. 1977 Apr;15(2):75-82. Available from: http://www.ncbi.nlm.nih.gov/pubmed/201462

2. Maartens G, Celum C, Lewin SR. HIV infection: Epidemiology, pathogenesis, treatment, and prevention. Lancet [Internet]. 2014;384(9939):258-71. Available from: http://dx.doi.org/10.1016/S0140-6736(14)60164-1

3. Tre`po C, Chan HLY, Lok A. Hepatitis B virus infection. Lancet. 2014;384(9959):2053-63.

4. Assefa $Y$, Jerene D, Lulseged S, Ooms G, Van Damme W. Rapid scale-up of antiretroviral treatment in Ethiopia: successes and system-wide effects. PLoS Med [Internet]. 2009 Apr;6(4):e1000056. Available from: http://www.ncbi.nlm.nih.gov/pubmed/19399154

5. HBV/HIV | Adult and Adolescent ARV Guidelines | AIDSinfo [Internet]. AIDSinfo Guidelines. 2016 [cited 2017 Sep 16]. Available from: https://aidsinfo.nih.gov/guidelines/html/1/adult-andadolescent-arv-guidelines/25/hbv-hiv 
6. Bataller R, Brenner DA. Liver fibrosis. J Clin Invest [Internet]. 2005 Feb;115(2):209-18. Available from: http://www.ncbi.nlm.nih.gov/pubmed/15690074

7. Chen C-J, Iloeje UH, Yang H-I. Long-Term Outcomes in Hepatitis B: The REVEAL-HBV Study. Clin Liver Dis [Internet]. 2007 Nov;11(4):797-816. Available from:

http://www.ncbi.nlm.nih.gov/pubmed/17981229

8. Unalp-Arida A, Ruhl CE. Liver fibrosis scores predict liver disease mortality in the United States population. Hepatology [Internet]. 2017 Jul;66(1):84-95. Available from:

http://www.ncbi.nlm.nih.gov/pubmed/28195363

9. Kim D, Kim WR, Kim HJ, Therneau TM. Association between noninvasive fibrosis markers and mortality among adults with nonalcoholic fatty liver disease in the United States. Hepatology [Internet]. 2013 Apr;57(4):1357-65. Available from: http://www.ncbi.nlm.nih.gov/pubmed/23175136

10. Germani G, Hytiroglou P, Fotiadu A, Burroughs AK, Dhillon AP. Assessment of Fibrosis and Cirrhosis in Liver Biopsies: An Update. Semin Liver Dis [Internet]. 2011 Feb;31(01):82-90. Available from: http://www.ncbi.nlm.nih.gov/pubmed/21344353

11. Bravo AA, Sheth SG, Chopra S. Liver Biopsy. N Engl J Med [Internet]. 2001 Feb;344(7):495-500. Available from: http://www.nejm.org/doi/abs/10.1056/NEJM200102153440706

12. Thampanitchawong P, Piratvisuth T. Liver biopsy:complications and risk factors. World $\mathrm{J}$ Gastroenterol [Internet]. 1999 Aug;5(4):301-4. Available from: http://www.ncbi.nlm.nih.gov/pubmed/11819452

13. Piccinino F, Sagnelli E, Pasquale G, Giusti G. Complications following percutaneous liver biopsy. A multicentre retrospective study on 68,276 biopsies. J Hepatol [Internet]. 1986;2(2):165-73. Available from: http://www.ncbi.nlm.nih.gov/pubmed/3958472

14. Wang Y, Hou J-L. Current strategies for quantitating fibrosis in liver biopsy. Chin Med J (Engl) [Internet]. 2015 Jan;128(2):252-8. Available from: http://www.ncbi.nlm.nih.gov/pubmed/25591571

15. Friedman LS. Controversies in liver biopsy: Who, where, when, how, why? Curr Gastroenterol Rep [Internet]. 2004 Jan;6(1):30-6. Available from: http://link.springer.com/10.1007/s11894-004-0023-4

16. Schmeltzer PA, Talwalkar JA. Noninvasive tools to assess hepatic fibrosis: ready for prime time? Gastroenterol Clin North Am [Internet]. 2011 Sep;40(3):507-21. Available from: http://www.ncbi.nlm.nih.gov/pubmed/21893271

17. GOMEZ-DOMINGUEZ E, MENDOZA J, RUBIO S, MORENO-MONTEAGUDO JA, GARCIA-BUEY L, MORENO-OTERO R. Transient elastography: a valid alternative to biopsy in patients with chronic liver disease. Aliment Pharmacol Ther [Internet]. 2006 Aug;24(3):513-8. Available from: http://www.ncbi.nlm.nih.gov/pubmed/16886917

18. D'Onofrio M, Crosara S, De Robertis R, Canestrini S, Demozzi E, Gallotti A, et al. Acoustic radiation force impulse of the liver. World J Gastroenterol [Internet]. 2013 Aug;19(30):4841-9. Available from: http://www.ncbi.nlm.nih.gov/pubmed/23946588

19. Ebinuma H, Saito H, Komuta M, Ojiro K, Wakabayashi K, Usui S, et al. Evaluation of liver fibrosis by transient elastography using acoustic radiation force impulse: comparison with Fibroscan®. J 
Gastroenterol [Internet]. 2011 Oct;46(10):1238-48. Available from:

http://www.ncbi.nlm.nih.gov/pubmed/21779759

20. Borsoi Viana MSV, Takei K, Collarile Yamaguti DC, Guz B, Strauss E. Use of AST platelet ratio index (APRI Score) as an alternative to liver biopsy for treatment indication in chronic hepatitis C. Ann Hepatol [Internet]. 8(1):26-31. Available from: http://www.ncbi.nlm.nih.gov/pubmed/19221530

21. Shin WG, Park SH, Jang MK, Hahn TH, Kim JB, Lee MS, et al. Aspartate aminotransferase to platelet ratio index (APRI) can predict liver fibrosis in chronic hepatitis B. Dig Liver Dis [Internet]. 2008 Apr;40(4):267-74. Available from: http://www.ncbi.nlm.nih.gov/pubmed/18055281

22. Ratziu V, Massard J, Charlotte F, Messous D, Imbert-Bismut F, Bonyhay L, et al. Diagnostic value of biochemical markers (FibroTest-FibroSURE) for the prediction of liver fibrosis in patients with nonalcoholic fatty liver disease. BMC Gastroenterol [Internet]. 2006 Feb;6:6. Available from: http://www.ncbi.nlm.nih.gov/pubmed/16503961

23. Lemoine M, Shimakawa Y, Nayagam S, Khalil M, Suso P, Lloyd J, et al. The gamma-glutamyl transpeptidase to platelet ratio (GPR) predicts significant liver fibrosis and cirrhosis in patients with chronic HBV infection in West Africa. Gut [Internet]. 2016 Aug;65(8):1369-76. Available from: http://www.ncbi.nIm.nih.gov/pubmed/26109530

24. Li Q, Song J, Huang Y, Li X, Zhuo Q, Li W, et al. The Gamma-Glutamyl-Transpeptidase to Platelet Ratio Does not Show Advantages than APRI and Fib-4 in Diagnosing Significant Fibrosis and Cirrhosis in Patients With Chronic Hepatitis B: A Retrospective Cohort Study in China. Medicine (Baltimore) [Internet]. 2016 Apr;95(16):e3372. Available from:

http://www.ncbi.nlm.nih.gov/pubmed/27100421

25. Sen S, Banerji D, Praharaj A, Chopra G, Gill S, Shrivastava R. Assessment of non-invasive models for liver fibrosis in chronic hepatitis $B$ virus related liver disease patients in resource limited settings. Indian J Pathol Microbiol [Internet]. 2013;56(3):196. Available from: http://www.ncbi.nlm.nih.gov/pubmed/24152493

26. Crossan C, Tsochatzis EA, Longworth L, Gurusamy K, Papastergiou V, Thalassinos E, et al. Costeffectiveness of noninvasive liver fibrosis tests for treatment decisions in patients with chronic hepatitis B in the UK: systematic review and economic evaluation. J Viral Hepat [Internet]. 2016 Feb;23(2):139-49. Available from: http://www.ncbi.nlm.nih.gov/pubmed/26444996

27. Tsochatzis EA, Crossan C, Longworth L, Gurusamy K, Rodriguez-Peralvarez M, Mantzoukis K, et al. Cost-effectiveness of noninvasive liver fibrosis tests for treatment decisions in patients with chronic hepatitis C. Hepatology [Internet]. 2014 Sep;60(3):832-43. Available from: http://www.ncbi.nlm.nih.gov/pubmed/25043847

28. Evatt BL. HIV Infection and thrombocytopenia. Curr Hematol Rep [Internet]. 2005 Mar;4(2):149-53. Available from: http://www.ncbi.nlm.nih.gov/pubmed/15720965

29. Belyhun Y, Maier M, Mulu A, Diro E, Liebert UG. Hepatitis viruses in Ethiopia: a systematic review and meta-analysis. BMC Infect Dis [Internet]. 2016 Dec;16(1):761. Available from:

http://www.ncbi.nlm.nih.gov/pubmed/27993129 
30. Nascimento FG, Tanaka PY. Thrombocytopenia in HIV-infected patients. Indian J Hematol Blood Transfus [Internet]. 2012 Jun [cited 2020 Jul 29];28(2):109-11. Available from:

/pmc/articles/PMC3332279/?report=abstract

31. Marks KM, Clarke RMA, Bussel JB, Talal AH, Glesby MJ. Risk factors for thrombocytopenia in hivinfected persons in the era of potent antiretroviral therapy. J Acquir Immune Defic Syndr [Internet]. 2009 Dec [cited 2020 Jul 29];52(5):595-9. Available from:

https://pubmed.ncbi.nlm.nih.gov/19734800/

32. Iroezindu MO, Agbaji OO, Daniyam CA, Isiguzo GC, Isichei C, Akanbi MO. Liver function test abnormalities in Nigerian patients with human immunodeficiency virus and hepatitis $B$ virus coinfection. Int J STD AIDS [Internet]. 2013 Jan [cited 2020 Jun 24];24(6):461-7. Available from: https://pubmed.ncbi.nlm.nih.gov/23970749/

33. Wandeler G, Mulenga L, Vinikoor MJ, Kovari H, Battegay M, Calmy A, et al. Liver fibrosis in treatmentnaïve HIV-infected and HIV/HBV co-infected patients: Zambia and Switzerland compared. Int J Infect Dis [Internet]. 2016 Oct 1 [cited 2020 Jun 24];51:97-102. Available from: https://pubmed.ncbi.nlm.nih.gov/27596685/

34. Price JC, Seaberg EC, Badri S, Witt MD, Acunto KD, Thio CL. MAJOR ARTICLE HIV Monoinfection Is Associated With Increased Aspartate Aminotransferase-to-Platelet Ratio Index, a Surrogate Marker for Hepatic Fibrosis. 2012;205:1005-13.

35. Stabinski L, Reynolds SJ, Ocama P, Laeyendecker O, Ndyanabo A, Kiggundu V, et al. High Prevalence of Liver Fibrosis Associated with HIV Infection: A Cross-Sectional Study in Rural Rakai, Uganda Lara. Antivir Ther. 2011;16(3):405-11.

36. Maponga TG, McNaughton AL, van Schalkwyk M, Hugo S, Nwankwo C, Taljaard J, et al. Treatment advantage in HBV/HIV coinfection compared to HBV monoinfection in a South African cohort. J Infect [Internet]. 2020 [cited 2020 Jun 24];81(1). Available from:

https://pubmed.ncbi.nlm.nih.gov/32360882/

37. Saha D, Pal A, Biswas A, Panigrahi R, Sarkar N, Sarkar J, et al. Characterization of treatment-naive HIV/HBV co-infected patients attending ART clinic of a tertiary healthcare centre in eastern India. PLoS One [Internet]. 2013 Aug 30 [cited 2020 Jun 24];8(8):e73613. Available from: http://www.ncbi.nlm.nih.gov/pubmed/24023688

38. Sarkar J, Saha D, Bandyopadhyay B, Saha B, Kedia D, Guha Mazumder DN, et al. Baseline characteristics of HIV \& Hepatitis B virus (HIV/HBV) co-infected patients from Kolkata, India. Indian J Med Res [Internet]. 2016 May 1 [cited 2020 Jun 24];143(MAY):636-42. Available from: https://pubmed.ncbi.nlm.nih.gov/27488008/

39. Huang SM, Cai WP, Hu FY, Lan Y, Liao BL, Chen YP, et al. Epidemiological and clinical characteristics of hepatitis B virus in HIV-infected patients in Guangdong, China. Int J STD AIDS [Internet]. 2016 Sep 1 [cited 2020 Jun 24];27(10):890-7. Available from:

http://www.ncbi.nlm.nih.gov/pubmed/26384940 


\section{Figures}

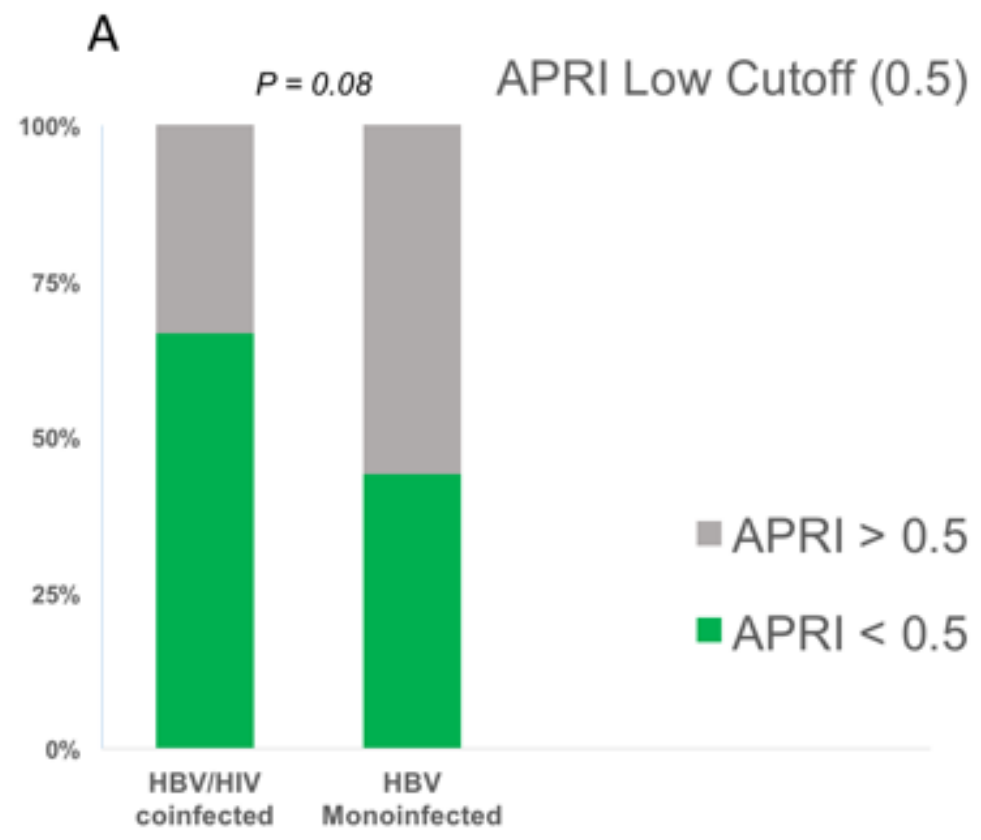

\section{Figure 1}

APRI score using a lower cutoff ( 0.5 ) comparison between HBV/HIV and HBV

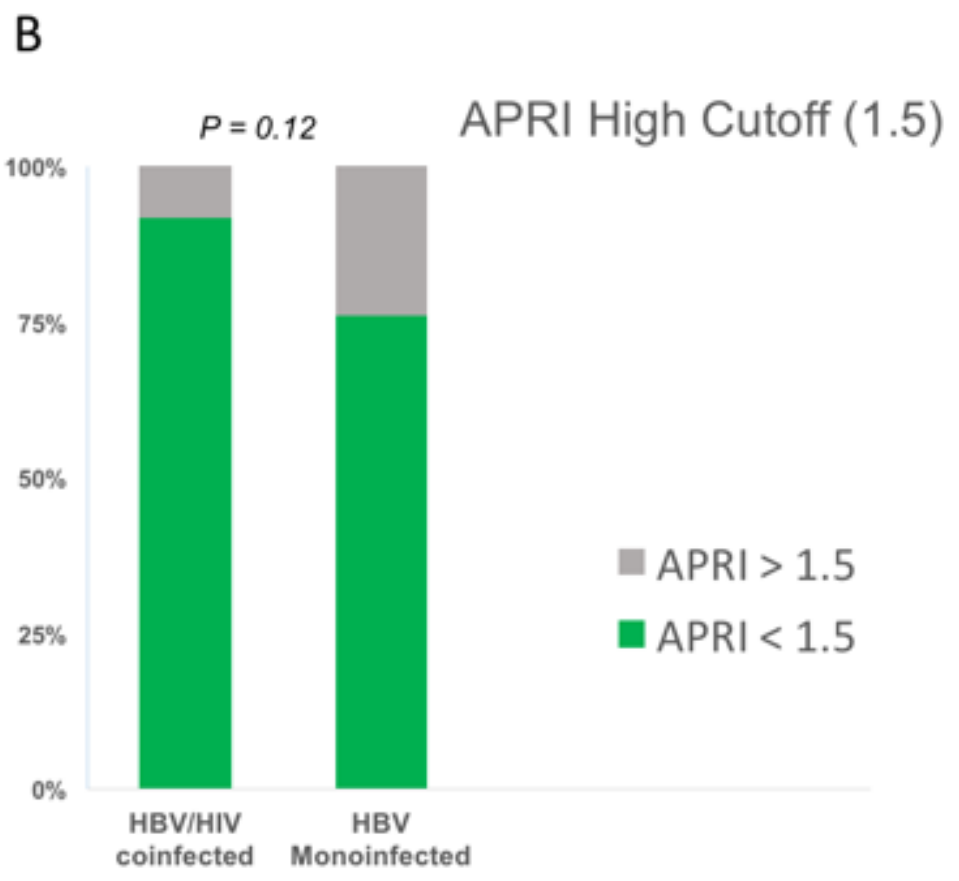

Figure 2 
APRI score using a higher cutoff ( 1.5 ) comparison between HBV/HIV and

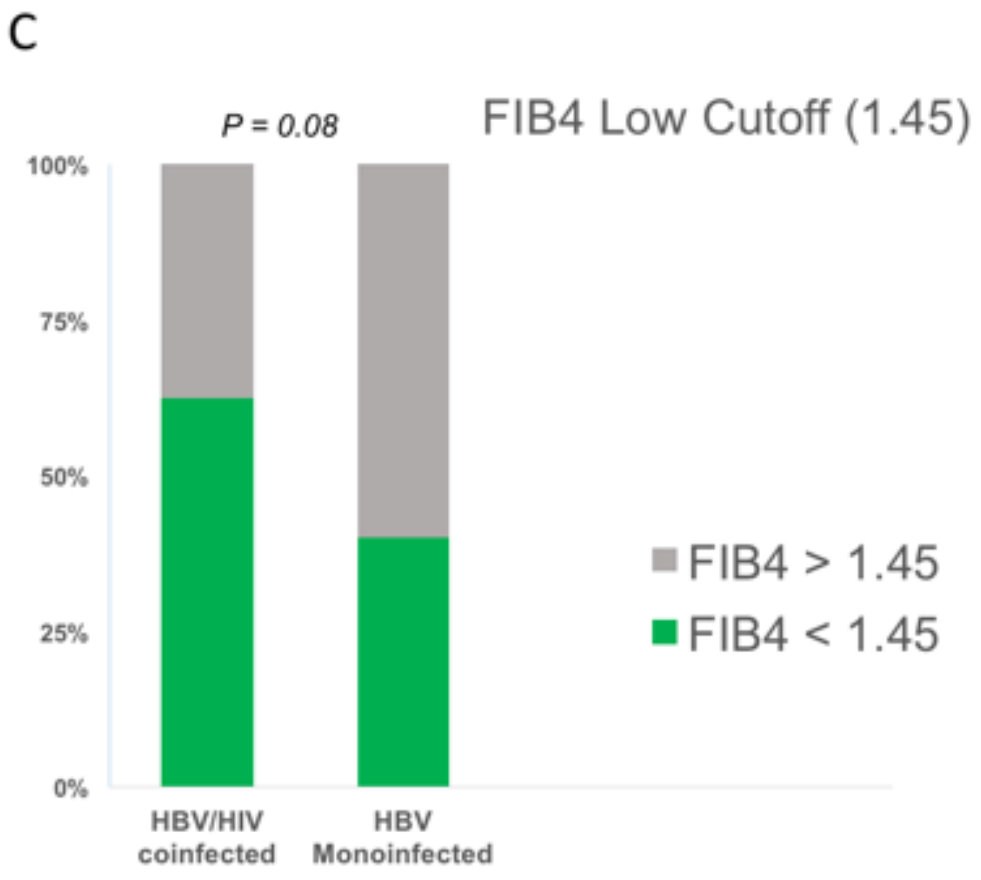

\section{Figure 3}

FIB4 score using a lower cutoff ( 1.45 ) comparison between HBV/HIV and HBV

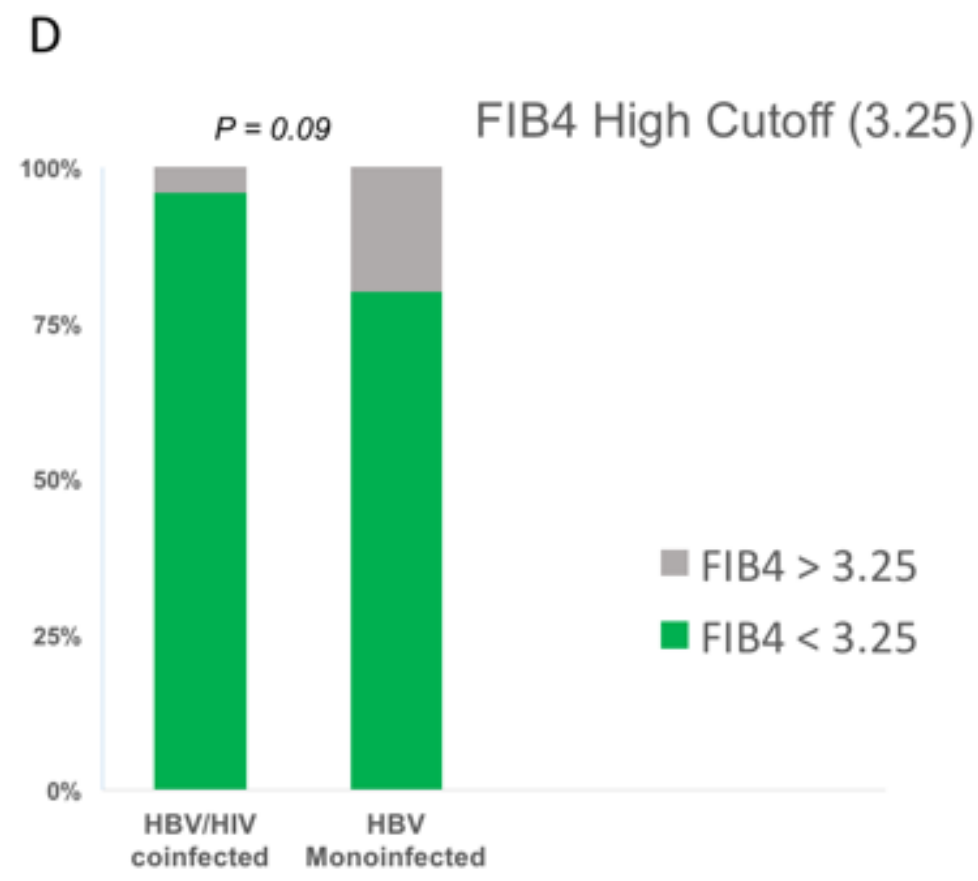

\section{Figure 4}

FIB4 score using a higher cutoff ( 3.25 ) comparison between HBV/HIV and HBV 


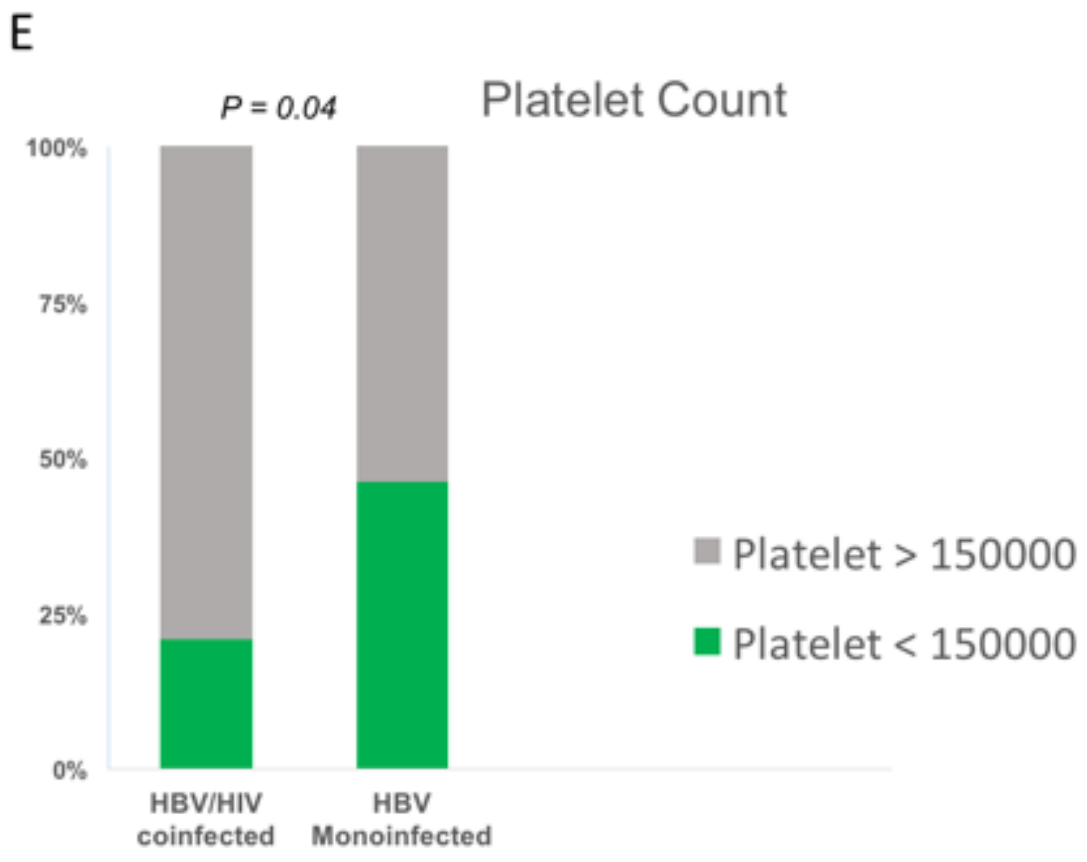

\section{Figure 5}

Platelet count comparison between HBV/HIV and HBV 